\title{
Association between temporary housing habitation after the 2011 Japan earthquake and mite allergen sensitization and asthma development.
}

\author{
Chiyako Oshikata $^{1}$, Maiko Watanabe ${ }^{2}$, Masatsugu Ishida ${ }^{3}$, Seiichi Kobayashi ${ }^{3}$, Kazuhiro \\ Hashimoto $^{4}$, Naoki Kobayashi ${ }^{5}$, Akiko Yamazaki ${ }^{6}$, Rumi Konuma ${ }^{7}$, Takeshi Kaneko ${ }^{8}$, \\ Yoichi Kamata $^{9}$, Shinichi Kuriyama ${ }^{10}$, Masaru Yanai ${ }^{3}$, and Naomi Tsurikisawa ${ }^{1}$ \\ ${ }^{1}$ Hiratsuka City Hospital \\ ${ }^{2}$ National Institute of Health Sciences \\ ${ }^{3}$ Japanese Red Cross Ishinomaki Hospital \\ ${ }^{4} \mathrm{FCG}$ Research Institute, Inc. \\ ${ }^{5}$ Azabu University \\ ${ }^{6}$ Iwate University \\ ${ }^{7}$ Tokyo Metropolitan Industrial Technology Research Institute \\ ${ }^{8}$ Yokohama City University Graduate School of Medicine \\ ${ }^{9}$ Faculty of Human Life Science \\ ${ }^{10}$ Tohoku University Graduate School of Medicine
}

September 28, 2020

\begin{abstract}
Background: We previously reported increased prevalence of asthma in adults who lived in temporary housing after the 2011 Great East Japan Earthquake. To investigate changes in asthma prevalence and mite-specific immunoglobulin E (IgE) titers in temporary housing residents from 2014 through 2019. Methods: We diagnosed asthma in Ishinomaki city temporary housing residents (age, ? 15 years) by using the GINA guidelines. We analyzed serum antigen-specific IgE levels to Dermatophagoides farinae (Der f), Dermatophagoides pteronyssinus (Der p), and Aspergillus fumigatus. Results: The prevalence of asthma exceeded $20 \%$ across all age groups throughout the study period. The proportion of study participants with a 'positive' antigen-specific IgE titer (i.e., ? $0.35 \mathrm{IUA} / \mathrm{mL}$ ) was higher in asthmatics than in non-asthmatics for Der $\mathrm{f}$ and Der $\mathrm{p}$ but not for Aspergillus fumigatus. Residents ? 50 years old who diagnosed asthma or non-asthma, the percentage with Der $\mathrm{f}$-specific IgE titer ? $0.10 \mathrm{IUA} / \mathrm{mL}$ was higher than in those with ? $0.35 \mathrm{IUA} / \mathrm{mL}$. Among study participants, asthma onset occurred before the earthquake, during residence in shelters or temporary housing, and, after 2016, moving out of temporary housing. The Der p-specific IgE level was positively correlated with the duration of temporary housing $(\mathrm{P}<0.05, \mathrm{r}=0.41)$ and inversely correlated with the time elapsed since moving out of temporary housing $(\mathrm{P}<0.05, \mathrm{r}=-0.35)$. Conclusions: Mite allergen sensitization was found in non-asthmatic temporary housing residents after the 2011 Japan earthquake and tsunami; asthma developed even after subjects moved out of temporary housing.
\end{abstract}

Key words: adult asthma, Dermatophagoides farinae, Dermatophagoides pteronyssinus, Aspergillus fumigatus, Great East Japan Earthquake, temporary housing, mite-specific IgE

Conflict of interest: No author has any conflict of interest to disclose. The work was not funded by a grant or any other external source of financial support. 
C. Oshikata, M. Watanabe, M. Ishida, S. Kobayashi, Hashimoto, N. Kobayashi, A. Yamazaki, R. Konuma, K T Kaneko, Y. Kamata, S. Kuriyama, M. Yanai, N. Tsurikisawa

Word count: 3499

\section{INTRODUCTION}

In the aftermath of natural disasters, such as floods and tsunamis, waterlogging and increased environmental humidity promote increased multiplication of bacteria and fungi, thereby increasing infectious diseases and worsening bronchial asthma [1,2]. Evidence from epidemiologic studies and meta-analyses suggests that exposure to intense indoor dampness and molds is associated with the development or exacerbation of bronchial asthma $[3,4,5]$.

House dust mites (HDMs), i.e., mites found in association with house dust, such as Dermatophagoides pteronyssinus $(\operatorname{Der} p)$ andDermatophagoides farinae $(\operatorname{Der} f$ ), are allergens that induce immunoglobulin $\mathrm{E}$ (IgE)-mediated sensitization and the subsequent development of bronchial hyperresponsiveness [6, 7, 8, 9]. HDM-specific IgE antibody titers correlate with airway hyperreactivity [7]. Exposure of sensitized people to Der $p$ or Der $f$ can trigger or exacerbate atopic asthma $[6,9,10]$.

Mites feed off spores of fungi and appear to have fungal food preferences, especially for Alternaria alternata ,Cladosporium sphaerospermun, and Wallemia sebi [11]. Increased indoor exposure to Der $p$ (allergen) and Cladosporium sphaerospermun (fungus) heightens the risk of development and persistence of atopy and asthma in adults [12]. After the 2010 Great Flood in Bangkok, Thailand, sensitization to dog and Alternaria (an indoor fungus) allergens increased during that year and for the next 3 years in children with asthma or allergic rhinitis. The trend in sensitization to HDMs showed that although the prevalence of sensitization was high ( $70 \%$ or greater) before the flood, it did not increase after the flood [13].

The Great East Japan Earthquake hit the island nation's east coast at 14:46 on March 11, 2011. This was the strongest earthquake ever recorded in Japan, with a magnitude of 9.0 at the epicenter, and was followed by a tsunami $[14,15]$. These natural calamities were followed by an increased prevalence of bronchial asthma and atopic dermatitis in children $[16,17]$ and the exacerbation of asthma in adults $[15,18]$.

The city of Ishinomaki, in eastern Miyagi Prefecture, sustained massive damage [18, 19], and because the earthquake and tsunami destroyed most residents' homes, many had to live in evacuation shelters or temporary housing. In addition, a nuclear accident at the Fukushima Daiichi Nuclear Power Plant after the earthquake and tsunami forced an evacuation, and levels of indoor airborne fungi were found to be increased in the evacuation zone [20]. We previously reported a rare case of allergic bronchopulmonary mycosis in a patient exposed to the fungusEurotium herbariorum while living in post-earthquake temporary housing in Ishinomaki [21].

To explore whether disasters, such as earthquakes and tsunamis, lead to the development or exacerbation of bronchial asthma in people who live in temporary housing after such natural calamities, we performed mass screening for respiratory and allergic diseases in current and previous residents (age, [?]15 years) of temporary housing in Ishinomaki and found that the prevalence of asthma in this population in 2014 was $24.9 \%$ [19], which was higher than that reported previously in Japan [22, 23].

In our previous study, the onset of asthma occurred after moving into temporary housing in $45.9 \%$ of asthmatics, and $71.4 \%$ of asthmatics had exacerbation of their disease after moving into temporary housing [19]. We showed that HDM allergen is an important cause of the development or exacerbation of asthma. We found that the antigen-specific IgE antibody titer against $\operatorname{Der} f$ was higher in asthmatic residents than in non-asthmatic residents; in addition, the percentage of non-asthmatics, especially those 50 years and older, with 'weakly positive' serum antigen-specific IgE antibody titers for $\operatorname{Der} f\left([?] \quad 0.10 \mathrm{IU}_{\mathrm{A}} / \mathrm{mL}\right.$ ) was higher than of non-asthmatics with 'positive' titers ([?] $\left.0.35 \mathrm{IU}_{\mathrm{A}} / \mathrm{mL}\right)$ [19].

Whether long-term habitation in temporary housing causes health hazards like asthma has not yet been reported. In this study, we performed group screening from 2014 through 2019 for respiratory and allergic 
diseases in adults (i.e., age, [?]15 years) who were living in or previously had lived for at least 1 year in temporary housing after the 2011 earthquake and tsunami; by 2019, many of the study participants had moved out of temporary housing. We examined the changes in mite-specific IgE antibody titer and the prevalence of asthma during the period of 2014 through 2019. We assessed whether living in the unique environment of temporary housing is associated with allergen sensitization and the development or exacerbation of asthma. We also studied the mechanism of asthma development in this adult population.

\section{METHODS}

\section{Study population}

We performed group screening for respiratory and allergic diseases in adults (age, [?]15 years) who currently were living in or previously had lived for at least 1 year in temporary housing in Ishinomaki, a city in Miyagi Prefecture that had suffered tremendous damage from the tsunami that occurred after the 2011 Great East Japan Earthquake. Our surveys covered the Kaisei temporary housing complex, the fourth and seventh Minamisakai complexes, the third and fourth Omori complexes, and the Jonai complex in 2014; the Kaisei complex, the Watanoha community center, and the Koganehama community center in 2015; the Kaisei complex, the Shinhebita meeting house around reconstruction houses, and the Japanese Red Cross Ishinomaki Hospital in 2016 through 2018; and the Shinhebita meeting house around reconstruction houses and the Japanese Red Cross Ishinomaki Hospital in 2019. Beginning in 2016, the increasing number of residents moving out of temporary housing and the consolidation of temporary housing in Ishinomaki city necessitated the change in examination venue to adapt to the situation and secure more examinees. A single 6-day survey between June and October 2014 (2 days each in June, July, and October); a 4-day survey each year from 2015 through 2018 between June and July; and a 2-day survey in June 2019 in the abovementioned places in Ishinomaki City were conducted. We recruited screening candidates by disseminating information about the survey through posters, leaflets, newspapers, and other media. Our group previously reported the survey results of 2014 [19]; the current study describes the survey results of 2015 through 2019.

\section{Survey details}

The same 3 respiratory specialists involved in the 2014 survey conducted the screening during 2014 through 2019 as well. These specialists interviewed each study participant; measured each resident's height, weight, and blood pressure; and obtained $10 \mathrm{~mL}$ of blood and a chest radiograph from each temporary housing resident; in addition, each study participant completed a medical questionnaire made by the authors. Residents suspected of having asthma or pulmonary emphysema according to findings from interviews or chest auscultation and X-ray underwent respiratory function tests and, if necessary, airway reversibility tests with inhaled salbutamol. From the test results, we diagnosed asthma or emphysema according to the Global INitiative for Asthma (GINA) guidelines [24] and identified participants in whom asthma was complicated by pulmonary emphysema (i.e., asthma-COPD overlap). Respiratory symptoms were investigated by using the European Community Respiratory Health Survey (ECRHS) questionnaire [25]. The contents of the questionnaire, including the extent of the damage in the participants' immediate environment at the time of the earthquake and the detailed past medical history of residents, can be found in previous our report [19].

The project was approved by the ethics committee of the University Hospital Medical Information Network (UMIN ID: UMIN000014376). We obtained written informed consent from each patient annually. The study was conducted in accordance with the principles and guidelines in the Declaration of Helsinki.

\section{Measures}

\section{Spirometry and airway reversibility}

To diagnosis asthma in adults who had or currently lived in temporary housing complexes, we examined lung function by using an electric spirometer (Minato Autospiro AS-302, Minato Medical Science Co., Ltd., Osaka, Japan). Each lung function test was performed 3 times, and the highest value was considered for analysis. The forced expiratory volume in 1 second $\left(\mathrm{FEV}_{1}\right)$ was expressed as percentage of the forced vital capacity. Residents suspected as having asthma underwent bronchodilator testing, which required 
the administration of $200 \mu \mathrm{g}$ of salbutamol via a nebulizer (DeVilbiss 646, DeVilbiss Healthcare, Somerset, PA, USA) by tidal breathing. Spirometry was performed at baseline and repeated at 15 and 30 minutes after salbutamol inhalation. Reversibility was defined (according to the GINA guidelines [24]) when FEV 1 increased by [?]200 $\mathrm{mL}$.

Antigen-specific IgE antibody levels

We measured the levels of antigen-specific IgE to two allergens (HDMs [Der $f$ and Der $p$ ] and Aspergillus fumigatus[a fungus]) by IMMULITE ${ }^{\circledR}$ 3gAllergy immunoassay (IMMULITE ${ }^{\circledR}$; Siemens Healthcare Diagnostics, Tokyo, Japan) [26]. Detection of specific IgE by IMMULITE ${ }^{\circledR}$ is expressed as quantitative units $\left(\mathrm{IU}_{\mathrm{A}} / \mathrm{mL}\right)$ and has a working range of 0.1 through $100 \mathrm{IU}_{\mathrm{A}} / \mathrm{mL}$. IMMULITE ${ }^{\circledR}$ results was defined as 'positive' when $\mathrm{IgE}$ values are [?]0.35 $\mathrm{IU}_{\mathrm{A}} / \mathrm{mL}$ (score 1 or higher) and 'weakly positive' when they are [?]0.10 $\mathrm{IU}_{\mathrm{A}} / \mathrm{mL}$ (score 0).

\section{Statistical Analysis}

Statistical comparisons of data from two groups were performed by using the Mann-Whitney U-test. Correlation coefficients were obtained by applying Spearman's rank correlation test. Statistical comparison between groups by using two-way ANOVA with repeated measures or with chi-squared testing revealed no significant differences. $P$ values $<0.05$ were considered statistically significant. All statistical analyses were performed by using SPSS for Windows, version 20 (IBM SPSS, Chicago, IL, USA).

\section{RESULTS}

Figure 1 depicts the year-wise distribution of the total number of people examined and the percentages of examinees still in temporary housing and those who had moved out. In both 2014 and 2015, more than $90 \%$ of the examinees resided in temporary housing. However, beginning in 2016, the number of temporary housing residents dwindled each year, such that in 2019, none of the participants still lived in temporary housing. In 2014, the average age of examinees was $61.3+-15.8$ years, and $37.2 \%$ of the total population were men, whereas in 2019, the overall average age was $67.6+-13.8$ years, and $43.8 \%$ of examinees were men (Figure 2 ). Therefore throughout the study, examinees included many elderly people, and the age distribution, in all the years that this survey was conducted, showed a peak at the sixth and seventh decades.

Beginning in 2016, the number of people who had moved out of temporary housing gradually increased. We therefore used 2 approaches - diagnoses by the respiratory specialists and assessment of asthma symptoms by using the ECRHS questionnaire (Table I) - to compare and analyze the prevalence of asthma in examinees after they moved into temporary housing and after they moved out. The prevalence of asthma according to physician diagnosis was similar to that from the ECRHS questionnaire and exceeded $20 \%$ across all ages from 2014 through 2019; there were no significant differences between the various age groups. In addition, according to both diagnostic methods, the prevalence of asthma in examinees who were living in temporary housing did not differ from that in those who had moved out. Figure 3 shows the prevalence of physiciandiagnosed asthma in examinees, by age, from 2014 through 2019. Although few examinees were younger than 40 years in 2017-2019 of the study, this group tended to have a high prevalence of asthma. In addition, throughout the observation period, the prevalence of physician-diagnosed asthma exceeded $20 \%$ in examinees 60 to 69 years old and was greater than $15 \%$ in those who were in the seventh and eighth decades (Fig. 3).

We then calculated the proportions of asthmatics in all age groups who had a 'positive' antigen-specific IgE titer (i.e., [?] $0.35 \mathrm{IU}_{\mathrm{A}} / \mathrm{mL}$ ) against $\operatorname{Der} f$, Der $p$, and Aspergillus fumigatus in the serum among all asthmatics; we similarly determined the percentages of non-asthmatic who had 'positive' IgE titers against these allergens (Table II). (We did not assayDer $f$-specific IgE levels in 2014 and 2015.) For Der $f$, the proportion of examinees with 'positive' titers was larger for asthmatics than non-asthmatics during 2014, 2017, 2018, and $2019(P<0.01)$; for $\operatorname{Der} p$, this subpopulation was larger in asthmatics than nonasthmatics in $2017(P<0.05), 2018(P<0.01)$, and $2019(P<0.01)$ (Table II). For Aspergillus fumigatus , the percentage of examinees with 'positive' titers did not differ between asthmatics and non-asthmatics, across all ages. In addition, the proportions of asthmatics with 'positive' antigen-specific IgE titers against 
$\operatorname{Der} f$ and $\operatorname{Der} p$ were high and varied between $21.1 \%$ and $52.9 \%$, compared with the number of asthmatics with a 'positive' antigen-specific IgE titer against Aspergillus fumigatus, which ranged from $2.5 \%$ to $8.8 \%$.

Across all age groups and years (except 2015), the percentage of asthmatic residents with serum antigenspecific IgE antibody titer [?] $0.35 \mathrm{IU}_{\mathrm{A}} / \mathrm{mL}$ against Der $f$ did not differ from that of those with an IgE level [?] $0.10 \mathrm{IU}_{\mathrm{A}} / \mathrm{mL}$ (Fig. 4 (a)). The proportion of asthmatic residents [?]50 years of age with serum antigenspecific IgE antibody titer for Der $f$ [?] $0.10 \mathrm{IU}_{\mathrm{A}} / \mathrm{mL}$ was larger than that of asthmatics with IgE level [?] $0.35 \mathrm{IU}_{\mathrm{A}} / \mathrm{mL}$ in $2014(P<0.05)$, in $2016(P<0.01)$, and in $2017(P<0.01)$ (Fig. $\left.4(\mathrm{a})\right)$. The percentage of non-asthmatic residents with serum antigen-specific IgE antibody titer [?] $0.10 \mathrm{IU}_{\mathrm{A}} / \mathrm{mL}$ against $\operatorname{Der} f$ was higher than for those with an $\mathrm{IgE}$ titer [?] $0.35 \mathrm{IU}_{\mathrm{A}} / \mathrm{mL}$ against $\operatorname{Der} f$ in all years except 2015 and across all age groups. This was particularly true for non-asthmatic residents [?]50 years of age compared with those [?] 49 years in 2014, 2016, 2017, and $2018(P<0.01)$ (Fig $4(\mathrm{~b})$ ). In addition, the proportions of examinees with $\mathrm{IgE}$ titer [?] $0.10 \mathrm{IU}_{\mathrm{A}} / \mathrm{mL}$ against $\operatorname{Der} f$ compared with [?] $0.35 \mathrm{IU}_{\mathrm{A}} / \mathrm{mL}$ differed for non-asthmatics in their eighth decade in $2014(P<0.05)$, in their seventh decade $(P<0.01)$ or eighth decade $(P<0.05)$ in 2016, and in their eighth decade in $2017(P<0.05)$ (Fig 4 (b)).

In 2014 and 2015, asthma onset occurred either before the earthquake, during stays in shelters, or after moving into temporary housing. In particular, asthma onset after moving into temporary housing comprised $76.5 \%$ of all cases in 2015, the highest percentage during 2014-2019. Thereafter the percentage of asthma cases that occurred after moving into temporary housing varied between $60.5 \%$ (in 2016) and $43.7 \%$ (in 2019). Beginning 2016, in addition to the previously described 3 subsets of asthma onset (i.e., before the earthquake, during stays in shelters, and after moving into temporary housing), people also developed asthma after moving out of temporary housing; this subpopulation accounted for $10.5 \%$ (in 2016) to $21.9 \%$ (in 2019) of all examinees during 2016-2019 (Fig 5).

The Der $f$ - specific serum IgE level in examinees in 2019 was correlated positively with the time elapsed since moving into temporary housing $(P<0.05, r=0.36)$ (Fig 6a, left panel) but not with the time elapsed since moving out of temporary housing (Fig 6a, right panel). Similarly, Der $p$ - specific IgE antibody level was positively correlated with the time elapsed since moving into temporary housing $(P<0.05, r=0.41)$ (Fig 6b, left panel) and inversely correlated with the time elapsed since moving out of temporary housing $(P<0.05, r=-0.35)$ (Fig 6b, right panel).

\section{DISCUSSION}

The prevalence of current asthma and asthma symptoms, such as wheezing, among Japanese adults aged 20-79 years was $10.1 \%$ [22]. The prevalence of lifetime asthma increased from $5.1 \%$ to $6.7 \%$ and that of current asthma increased from 1.5\% to 3.4\% during the years 1999 through 2006 among adults in Fujieda, Japan [23].

In our survey (2014-2019), notwithstanding that the number of medical examinations differed each year, the prevalence of physician-diagnosed asthma among adults aged [?] 15 years who had lived for at least 1 year in temporary housing exceeded $20 \%$ across all age groups - more than double the rate reported previously in Japan. Our results also show that the prevalence of asthma did not differ between residents still living in temporary housing and those who had moved out of temporary housing; this, therefore, implies that moving out of temporary housing does not reduce the prevalence of asthma (Table I).

In the 2014 survey we reported [19], the rates of depression among victims of the Great East Japan Earthquake were more than twice as high as that of the 1995 Great Hanshin-Awaji Earthquake [27], but there were no significant differences in mental stress-related illnesses between asthmatics and non-asthmatics. The development and exacerbation of asthma in our survey population may not have been directly related to the effects of post-earthquake mental stress.

The development and exacerbation of asthma has been reported to be associated with inhaled allergens, such as HDMs, in both children and adults [6, 7, 8, 9, 10]. Our 6-year screening study revealed that HDMs-not Aspergillus fumigatus - were the causative allergens that resulted in symptoms of asthma. The proportion of 
non-asthmatics with serum antigen-specific IgE antibody titers for $\operatorname{Der} f$ [?] $0.10 \mathrm{IU}_{\mathrm{A}} / \mathrm{mL}$ (defined as 'weak positive') was larger than that of non-asthmatics with serum antigen-specific IgE antibody titers forDer $f$ [?] $0.35 \mathrm{IU}_{\mathrm{A}} / \mathrm{mL}$ (defined as 'positive') across all age groups and years, except 2015 (Fig 4b). However, the percentages of asthmatics with serum antigen-specific $\operatorname{IgE}$ antibody titers for $\operatorname{Der} f$ [?] $0.10 \mathrm{IU} \mathrm{A}_{\mathrm{A}} / \mathrm{mL}$ and those with an IgE titer [?] $0.35 \mathrm{IU}_{\mathrm{A}} / \mathrm{mL}$ were similar across all age groups and years, except 2016 (Fig 4a). Our results show that compared with asthmatics, non-asthmatics showed greater weak sensitization to HDMs, defined as antigen-specific IgE antibody titers for $\operatorname{Der} f[?] 0.10 \mathrm{IU}_{\mathrm{A}} / \mathrm{mL}$, over the 6 -year observation period. Furthermore, a greater proportion of asthmatic residents [?] 50 years of age had 'weak positive' Der $f$ serum IgE titers than 'positive' titers in 2014, 2016, and 2017 (Fig 4a). These results indicate that both asthmatic and non-asthmatic residents [?] 50 years of age are more susceptible to weak sensitization to Der $f$ than are adults [?] 49 years of age who are former or current residents of temporary housing.

It is unclear what proportion of HDM-sensitized but otherwise healthy people go on to develop asthma. In a previous study [28], mite-specific $\mathrm{IgE}$ antibody ([?] $0.35 \mathrm{IU}_{\mathrm{A}} / \mathrm{mL}$ ) was detected in $21.8 \%$ of 234 patients with a mean age of $29.4+-6.4$ years and no history of respiratory disease. In addition, the mite-specific IgE antibody titer correlated with increased airway hyperresponsiveness $(r=0.52, P<0.018)$ [28]. Of 308 students who were non-smokers and had no history of allergic disease, $34.2 \%$ had a mite-specific $\operatorname{IgE}$ radioallergosorbent test (RAST) score of 2 or higher [29]. In an analysis of total serum IgE levels throughout childhood, $15.2 \%$ of the 469 non-atopic subjects (age, 1-20 years), defined as having a negative response to 5 airborne antigens (HDM, cat, dog, mixed grass, birch pollen) and 4 food allergens (cow milk, hen eggs, wheat, soy), had high total IgE levels [30].

Allergen sensitization can occur and subsequent asthma can develop in subjects without respiratory disease or allergic disease symptoms. Our results show that sensitization to HDM allergens was high in temporary housing residents, especially in those [?] 50 years of age.

The prevalence of asthma in our study population did not necessarily decrease after moving out of temporary housing. In fact, new cases of asthma were diagnosed not only after examinees moved into temporary housing but also after they moved out; these latter cases occurred every year since 2016. This suggests that sensitization to HDM allergens while living in temporary housing led to the development of asthma due to these environmental factors after residents moved out.

Serum antigen-specific IgE antibody titers for Der $p$ [?] $0.10 \mathrm{IU}_{\mathrm{A}} / \mathrm{mL}$ assayed in 2019 were positively correlated with the duration of temporary housing and negatively correlated with the time elapsed since moving out of temporary housing. These findings indicate that HDM sensitization intensifies when temporary housing is prolonged and that sensitization becomes weaker on moving out. This pattern implies that HDM sensitization can be decreased by moving out of temporary housing, thereby reducing HDM allergen exposure. We considered that allergen sensitization could be improved or asthma could be newly developed due to the difference in mite allergen exposure in the living environment after moving out of temporary housing. Although prolonged occupancy of temporary housing is rare, this study is useful in explaining one mechanism of allergic sensitization and asthma development.

Due to allergen avoidance through environmental improvement after floods, asthma symptoms in children diminished [31] and respiratory function increased [32]. Similarly, we reported in case presentation that the temporary housing environment in Ishinomaki city has improved greatly, thereby decreasing fungal exposure and ameliorating symptoms of allergic bronchopulmonary mycosis [21]. A meta-analysis showed that bronchial hyperresponsiveness decreased after mite-impermeable mattress covers were provided to patients previously exposed to high levels of Der 1 [33]. Allergen avoidance by changes in the living environment after an earthquake might similarly improve asthma exacerbation or development.

This study showed asthma prevalence rates in temporary housing residents over a 6 -year period after the Great East Japan Earthquake. Moreover, HDM allergen sensitization was found in non-asthmatics; asthma developed even after residents had moved out of temporary housing; and, in some cases, Der $p$-specific IgE antibody titers decreased after residents moved out of temporary housing. Future interventional studies for 
allergen avoidance by residents with a history of temporary housing are warranted to verify the usefulness of environmental maintenance in reducing HDM allergen levels and diminishing the symptoms of asthma and to determine the long-term prognosis of asthma.

\section{Acknowledgments}

We thank Ms. Yumiko Takeuchi and Ms. Masayo Morie for performing the pulmonary function tests, Ms. Yuka Taira for blood sampling, and Ms. Takako Oi for acting as an examination assistant.

\section{FUNDING}

This study was funded by a Health and Labor Sciences Research Grant (Research on Health Security Control, H24-Kenki-20wakate-001).

\section{References}

1. Carlos WG, Cruz CD, Jamil S, Kipen H, Rose C. Mold-Specific Concerns Associated with Water Damage for Those with Allergies, Asthma, and Other Lung Diseases. Am J Respir Crit Care Med. 2017;196 13-4

2. Johanning E, Auger P, Morey PR, Yang CS, Olmsted E. Review of health hazards and prevention measures for response and recovery workers and volunteers after natural disasters, flooding, and water damage: mold and dampness. Environ Health Prev Med. 2014;19:93-9

3. Jaakkola MS, Nordman H, Piipari R, Uitti J, Laitinen J, Karjalainen A, et al. Indoor dampness and molds and development of adult-onset asthma: a population-based incident case-control study.Environ Health Perspect. 2002;110:543-7

4. Mendell MJ, Mirer AG, Cheung K, Tong M, Douwes J. Respiratory and allergic health effects of dampness, mold, and dampness-related agents: a review of the epidemiologic evidence.Environ Health Perspect. 2011;119:748-56

5. Park JH, Cox-Ganser JM, Kreiss K, White SK, Rao CY. Hydrophilic fungi and ergosterol associated with respiratory illness in a water-damaged building. Environ Health Perspect. 2008;116:45-50

6. Platts-Mills AE, Platts-Mills TA, Vervloet D, Thomas WR, Aalberse RC, Chapman MD. Indoor allergens and asthma: report of the Third International Workshop.J Allergy Clin Immunol 1997;100:S2-24

7. Barnig C, Purohit A, Casset A, Sohy C, Lieutier-Colas F, Sauleau E, et al. Nonallergic airway hyperresponsiveness and allergen-specific IgE levels are the main determinants of the early and late asthmatic response to allergen. J Investig Allergol Clin Immunol. 2013;23:267-74

8. Kerkhof M, Postma DS, Schouten JP, de Monchy JG. Allergic sensitization to indoor and outdoor allergens and relevance to bronchial hyperresponsiveness in younger and older subjects. Allergy. 2003;58:1261-7

9. Wong GW, Li ST, Hui DS, Fok TF, Zhong NS, Chen YZ, Lai CK. Individual allergens as risk factors for asthma and bronchial hyperresponsiveness in Chinese children. Eur Respir J. 2002;19:288-93.

10. Salo PM, Arbes SJ Jr, Crockett PW, Thorne PS, Cohn RD, Zeldin DC. Exposure to multiple indoor allergens in US homes and its relationship to asthma. J Allergy Clin Immunol. 2008;121:678-84

11. Naegele A, Reboux G, Scherer E, Roussel S, Millon L. Fungal food choices of Dermatophagoides farinae affect indoor fungi selection and dispersal. Int J Environ Health Res. 2013;23:91-5

12. Matheson MC, Abramson MJ, Dharmage SC, Forbes AB, Raven JM, Thien FC, et al. Changes in indoor allergen and fungal levels predict changes in asthma activity among young adultsClin Exp Allergy. 2005;35:907-13

13. Visitsunthorn N, Chaimongkol W, Visitsunthorn K, Pacharn P, Jirapongsananuruk O. Great flood and aeroallergen sensitization in children with asthma and/or allergic rhinitis. Asian Pac J Allergy Immunol. 2018;36:69-76 
14. Furukawa K, Arai H. Earthquake in Japan.Lancet.2011;377(9778):1652

15. Ohkouchi S, Shibuya R, Yanai M, Kikuchi Y, Ichinose M, Nukiwa T. Deterioration in regional health status after the acute phase of a great disaster: respiratory physicians' experiences of the Great East Japan Earthquake. Respir Investig. 2013;51:50-5

16. Ishikuro M, Matsubara H, Kikuya M, Obara T, Sato Y, Metoki H, et al. Disease prevalence among nursery school children after the Great East Japan earthquake.BMJ Glob Health. 2017;2:e000127.

17. Miyashita M, Kikuya M, Yamanaka C, Ishikuro M, Obara T, Sato Y, et al. Eczema and Asthma Symptoms among Schoolchildren in Coastal and Inland Areas after the 2011 Great East Japan Earthquake: The ToMMo Child Health Study. Tohoku J Exp Med. 2015;237:297-305

18. Yamanda S, Hanagama M, Kobayashi S, Satou H, Tokuda S, Niu K, et al. The impact of the 2011 Great East Japan Earthquake on hospitalisation for respiratory disease in a rapidly aging society: a retrospective descriptive and cross-sectional study at the disaster base hospital in Ishinomaki.BMJ Open . 2013; 3. pii: e000865

19. Oshikata C, Watanabe M, Ishida M, Kobayashi S, Hashimoto K, Kobayashi N, et al. Increase in asthma prevalence in adults in temporary housing after the Great East Japan Earthquake. International Journal of Disaster Risk Reduction. 2020 DOI; 10.1016/j.ijdrr.2020.101696

20. Shinohara N, Tokumura M, Hashimoto K, Asano K, Kawakami Y. Fungal levels in houses in the Fukushima Daiichi Nuclear Power Plant evacuation zone after the Great East Japan Earthquake. J Air Waste Manag Assoc . 2017;67:1106-14

21. Oshikata C, Watanabe M, Saito A, Ishida M, Kobayashi S, Konuma R, et al. Allergic Bronchopulmonary Mycosis due to Exposure to Eurotium herbariorum after the Great East Japan Earthquake. Prehosp Disaster Med . 2017;32:688-90

22. Fukutomi Y, Nakamura H, Kobayashi F, Taniguchi M, Konno S, Nishimura M, et al. Nationwide cross-sectional population-based study on the prevalences of asthma and asthma symptoms among Japanese adults. Int Arch Allergy Immunol.2010;153:280-7

23. Fukutomi Y, Taniguchi M, Watanabe J, Nakamura H, Komase Y, Ohta K, et al. Time trend in the prevalence of adult asthma in Japan: findings from population-based surveys in Fujieda City in 1985, 1999, and 2006. Allergol Int.2011;60:443-8

24. GINA. Global Strategy for Asthma Management and Prevention,Global Initiative for Asthma 2014. Available from: http://www.ginasthma.org/.

25. de Marco R, Zanolin ME, Accordini S, Signorelli D, Marinoni A, Bugiani M, et al. A new questionnaire for the repeat of the first stage of the European Community Respiratory Health Survey: a pilot study.Eur Respir J. 1999;14:1044-8

26. Watanabe M, Hirata H, Arima M, Hayashi Y, Chibana K, Yoshida N, et al. Measurement of Hymenoptera venom specific IgE by the IMMULITE 3gAllergy in subjects with negative or positive results by ImmunoCAP.Asia Pac Allergy. 2012;2:195-202

27. Maruyama S, Kwon YS, Morimoto K. Seismic intensity and mental stress after the Great Hanshin-Awaji Earthquake.Environ Health Prev Med. 2001;6:165-9

28. Nogalo B, Miric M, Maloca I, Turkalj M, Plavec D. Normal variation of bronchial reactivity in nonasthmatics is associated with the level of mite-specific IgE. $J$ Asthma. 2008;45:273-7

29. Obase Y, Shimoda T, Mitsuta K, Matsuo N, Matsuse H, Kohno S. Sensitivity to the house dust mite and airway hyperresponsiveness in a young adult population. Ann Allergy Asthma Immunol. 1999;83:305-10 
30. Sacco C, Perna S, Vicari D, Alfò M, Bauer CP, Hoffman U, et al. Growth curves of "normal" serum total IgE levels throughout childhood: A quantile analysis in a birth cohort. Pediatr Allergy Immunol.2017;28:52534

31. Kercsmar CM, Dearborn DG, Schluchter M, Xue L, Kirchner HL, Sobolewski J, et al. Reduction in asthma morbidity in children as a result of home remediation aimed at moisture sources. Environ Health Perspect. 2006;114:1574-80

32. Johanning E, Landsbergis P, Gareis M, Yang CS, Olmsted E. Clinical experience and results of a Sentinel Health Investigation related to indoor fungal exposure.Environ Health Perspect. 1999;107 Suppl 3:489-94

33. van Boven FE. Effectiveness of mite-impermeable covers: a hypothesis-generating meta-analysis. Clin Exp Allergy. 2014;44:1473-83

Table 1. Year-wise distribution of prevalence of asthma in examinees who were living in or had lived in temporary housing

\begin{tabular}{lll}
\hline & & Prevalence of asthma (no. with asthma present/ no. with \\
\hline Screening year & Housing status & ECRHS questionnaire \\
2014 & Living in or moved out of temporary housing & $75 / 262(22.3)$ \\
2015 & Living in or moved out of temporary housing & $44 / 173(20.3)$ \\
2016 & Living in or moved out of temporary housing & $64 / 220(22.5)$ \\
& Living in temporary housing & $26 / 88(22.8)$ \\
2017 & Moved out of temporary housing & $38 / 132(22.4)$ \\
& Living in or moved out of temporary housing & $34 / 130(20.7)$ \\
& Living in temporary housing & $10 / 47(17.5)$ \\
2018 & Moved out of temporary housing & $24 / 83(22.4)$ \\
& Living in or moved out of temporary housing & $35 / 102(25.5)$ \\
& Living in temporary housing & $4 / 11(26.7)$ \\
2019 & Moved out of temporary housing & $31 / 91(25.4)$ \\
& Living in or moved out of temporary housing & $30 / 107(21.9 \%)$ \\
& Living in temporary housing & 0 \\
& Moved out of temporary housing & $30 / 107(21.9 \%)$ \\
\hline
\end{tabular}

Table 2. Numbers of examinees (asthmatics and non-asthmatics) in all age groups who had or did not have a 'positive' serum antigen-specific IgE level (i.e., [?] $0.35 \mathrm{IU}_{\mathrm{A}} / \mathrm{mL}$ ) againstDermatophagoides farinae (Der $f$ ), Dermatophagoides pteronyssinus (Der $p$ ), and Aspergillus fumigatus

\begin{tabular}{cll}
\hline Year No. of asthmatics & No. of asthmatics with 'positive' IgE titer (RAST), & No. of asthmatics with 'positive' IgE tite \\
& no. of asthmatics without 'positive' IgE titer & no. of asthmatics without 'positive' IgE \\
& (\% of screened population & (\% of screened population \\
& with 'positive' titer) & wer 'positive' titer) \\
& Der $f$ & Der $p$
\end{tabular}

201484

$29,53(35.4)$

$19,41(31.7)$

$2015 \quad 63$

17, 59 (22.4)

$2016 \quad 76$

ND

ND

16, $60(21.1)$ 


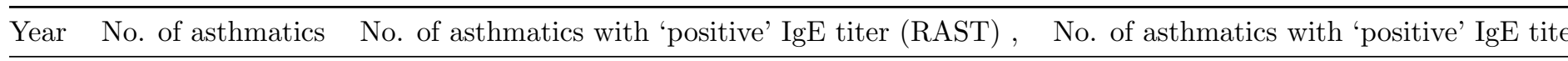

$17,31(35.4)$

$2017 \quad 48$

$18,16(52.9)$

$2018 \quad 34$

$15,17(46.9)$

$2019 \quad 32$

$16,32(33.3)$

$18,16(52.9)$

$13,19(40.6)$

$P<0.05$ was considered statistically significant.

Chi-squared testing revealed no significant differences in the values for the two groups.

RAST, radioallergosorbent test; ND, not determined; NS, not significant

Figure legends

Figure 1. Year-wise distribution of number of examinees and classification by residence at the time of examination. Gray, examinees living in temporary housing; white, examinees who had moved out of temporary housing.

Figure 2 . Age distribution of examinees screened from 2014 through 2019.

Figure 3 . Age-wise prevalence of asthma in examinees (2014-2019). Asthma was diagnosed by respiratory specialists according to the Global Initiative for Asthma (GINA) guidelines.

Figure 4 . Age-wise distribution of serum IgE level (estimated by radioallergosorbent test [RAST]) to Der $f$ [?] $0.35 \mathrm{IU}_{\mathrm{A}} / \mathrm{mL}$ versus serum $\operatorname{IgE}(\mathrm{RAST})$ to $\operatorname{Der} f$ [?] $0.10 \mathrm{IU}_{\mathrm{A}} / \mathrm{mL}$ in asthmatics (a) and non-asthmatics (b). Chi-squared testing revealed no significant differences in the values for the two groups. Gray shading indicates examinees older than 50 years.

Figure 5 . Timing of onset of asthma from 2014 through 2019. Vertical stripes, before the earthquake; solid white, during stays in shelters; diagonal stripes, after moving into temporary housing; solid black, after moving out of temporary housing. There were 84 examinees with asthma in 2014, 63 in 2015, 76 in 2016, 48 in 2017, 34 in 2018, and 32 in 2019. There were 10 cases when the onset of asthma was unknown in 2014 and 1 in 2015.

Figure 6 (a) . Correlation between $\log \operatorname{Der} f$ - specific IgE antibody level in serum in examinees in 2019 and time elapsed since moving into (left panel) and out of (right panel) temporary housing.Der $f$ - specific $\operatorname{IgE}$ antibody level at the time of examination in 2019 was correlated with duration of temporary housing $(P<$ $0.05, r=0.36$ ) (left panel) but not with time elapsed since moving out of temporary housing (right panel).

Figure 6 (b) . Correlation between $\log$ Der $p$ - specific IgE antibody level in serum in examinees in 2019 and time elapsed since moving into (left panel) and out of (right panel) temporary housing. Correlation coefficients were obtained by using Spearman's rank correlation test. 
Figure 1

Total number

of examinees

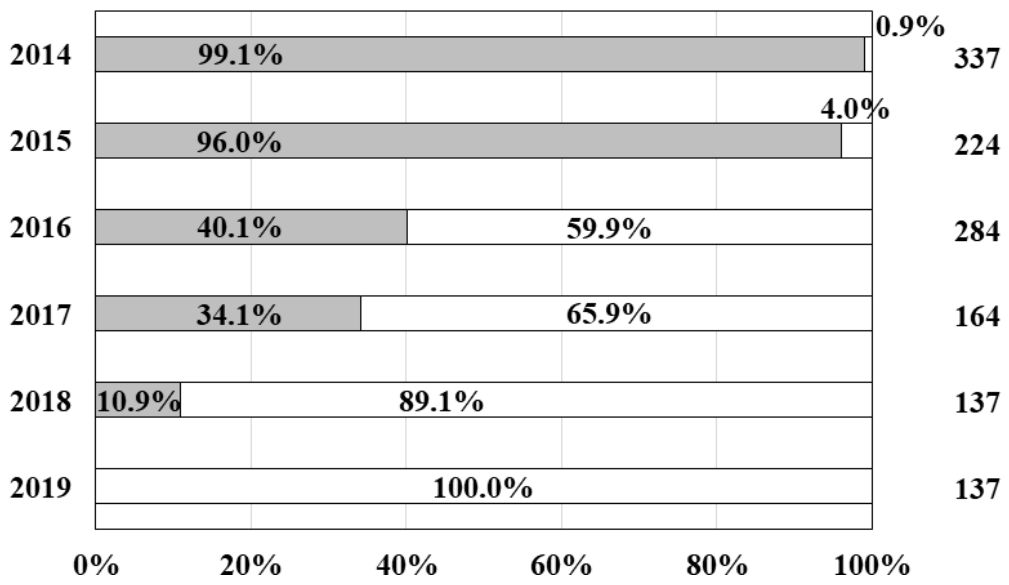

Figure 2

2014: 337 people ; men, $37.2 \%$; age, $61.3 \pm 15.8$ years

(No. of people)

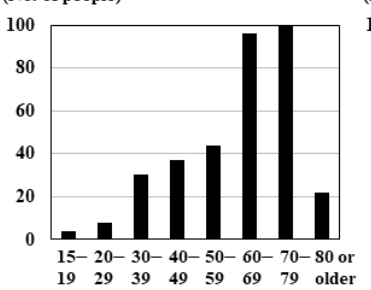

\begin{tabular}{l}
$15-20-30-40-50-60-70-80$ or \\
$19 \quad 29 \quad 39$ \\
\hline
\end{tabular}

2017: 164 people ; men, $44.5 \%$; age, $64.7 \pm 15.0$ years

(No. of people)

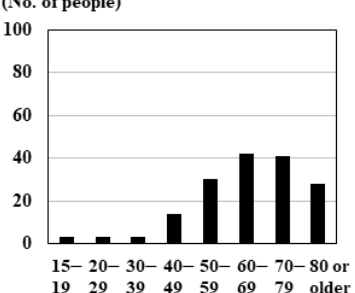

2015: 224 people ; men, $38.7 \%$; age, $64.4 \pm 14.6$ years

(No. of people)

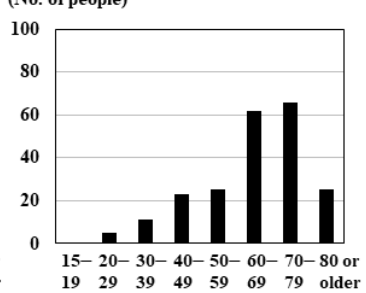

2018: 137 people ; men, $45.3 \%$; age, $66.8 \pm 13.0$ years

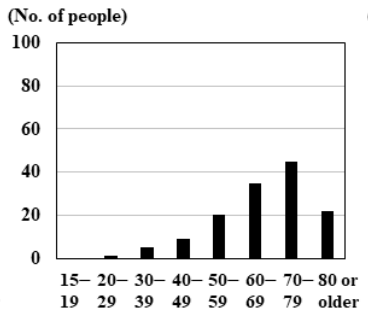

2016: 284 people ; men, $38.6 \%$; age, $65.2 \pm 13.7$ years

(No. of people)

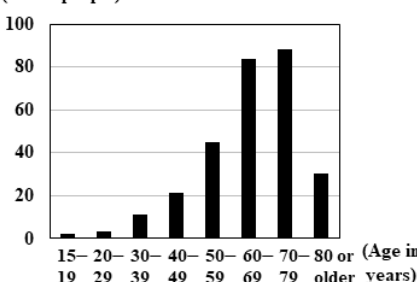

2019: 137 people ; men, $43.8 \%$; ge, $67.6 \pm 13.8$ years

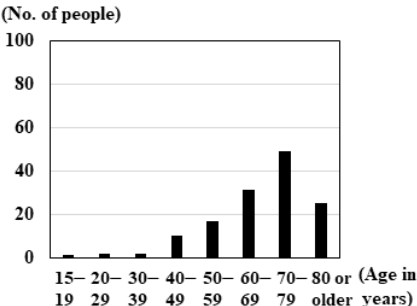




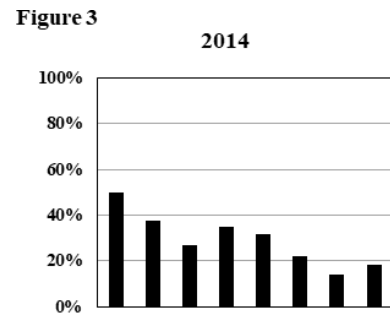

$\begin{array}{lllllllll}\text { Number } & 4 & 8 & 30 & 37 & 44 & 96 & 100 & 22\end{array}$ (Age in 15- 20- 30- 40- 50- 60- 70- 80 or $\begin{array}{lllllllll}\text { years) } & 19 & 29 & 39 & 49 & 59 & 69 & 79 & \text { older }\end{array}$

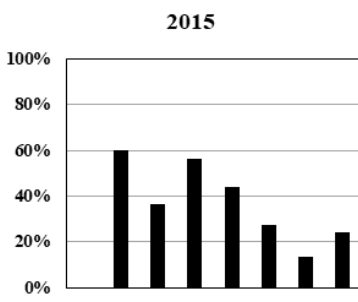

$\begin{array}{llllllll}0 & 5 & 11 & 23 & 25 & 62 & 66 & 25\end{array}$ $15-20-30-40-50-60-70-80$ or
$19 \quad 29 \quad 39 \quad 49 \quad 59 \quad 69 \quad 79$ older

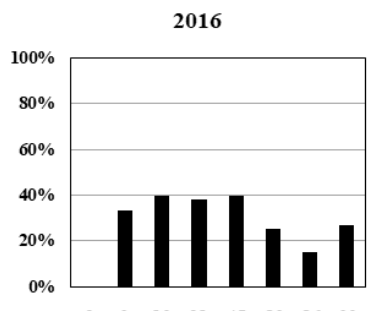

$\begin{array}{llllllll}2 & 3 & 10 & 21 & 45 & 83 & 86 & 30\end{array}$ $15-20-30-40-50-60-70-80$ or
2017

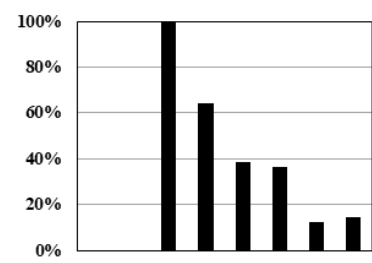

$\begin{array}{lllllllll}\text { Number } & 3 & 3 & 3 & 14 & 31 & 41 & 41 & 28\end{array}$ (Age in 15- 20- 30- 40-50- 60- 70- 80 or $\begin{array}{lllllllll}\text { years) } & 19 & 29 & 39 & 49 & 59 & 69 & 79 & \text { older }\end{array}$
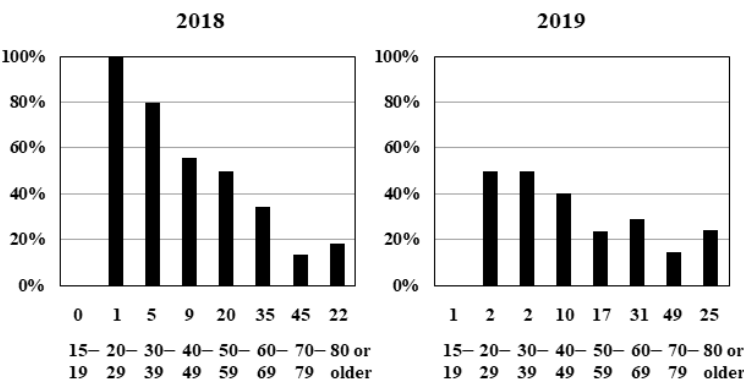

Figure 4 (a)

Serum IgE (RAST) for Der $f \geq 0.35 \mathrm{IU}_{\mathrm{A}} / \mathrm{mL}$ (asthmatics)

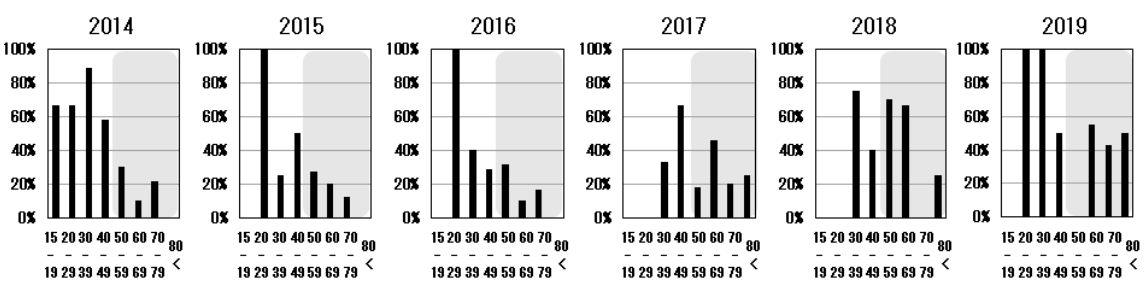

Serum IgE (RAST) for Der $f \geq 0.10 \mathrm{IU}_{\mathrm{A}} / \mathrm{mL}$ (asthmatics)
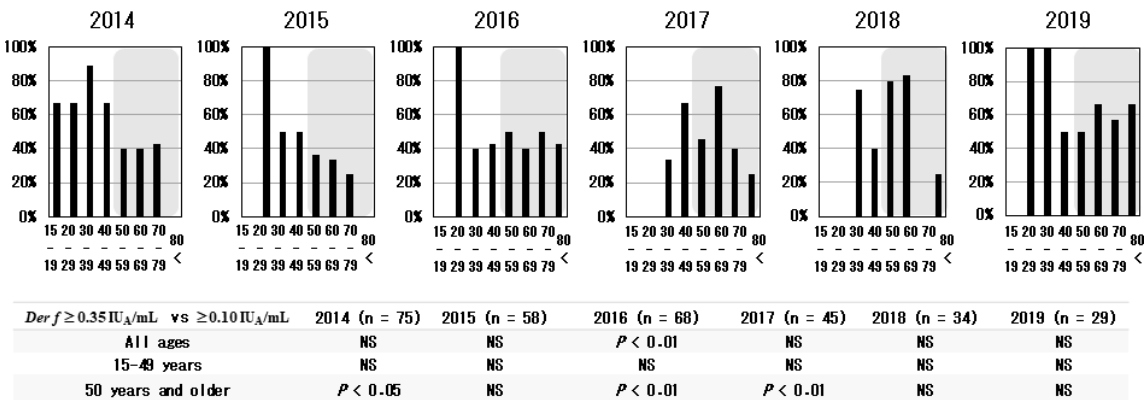
Figure 4 (b)

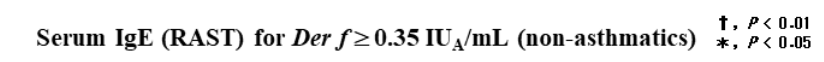

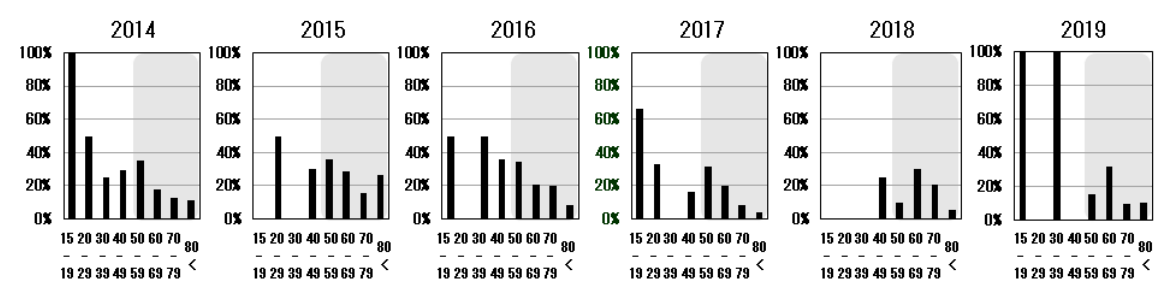

Serum IgE (RAST) for Der $f \geq 0.10 \mathrm{IU}_{\mathrm{A}} / \mathrm{mL}$ (non-asthmatics)

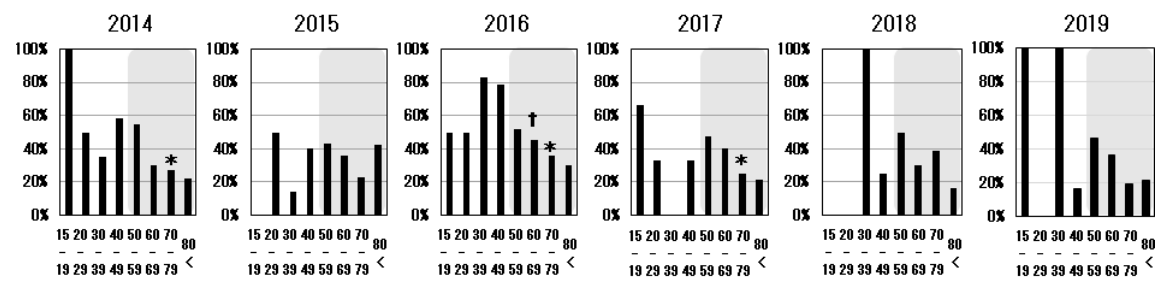

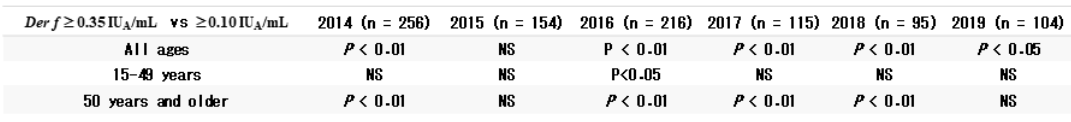

Figure 5

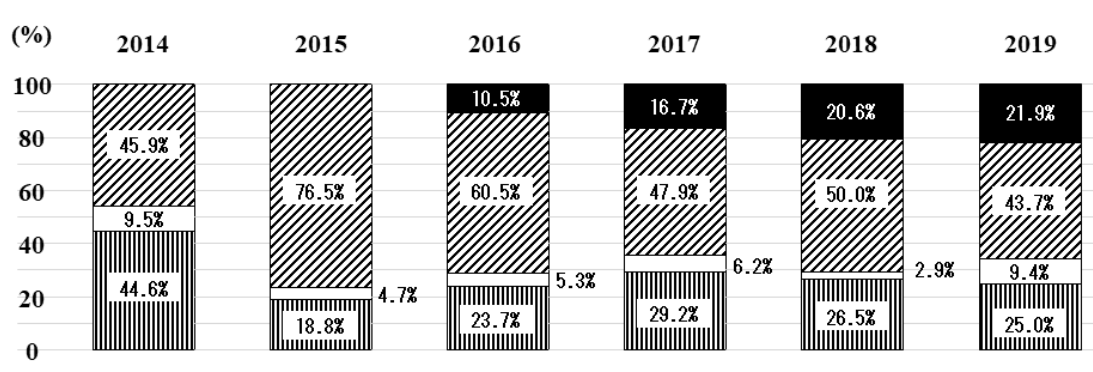

||l||l|| before the earthquake $\square$ while in shelters

after moving out of temporary housing 

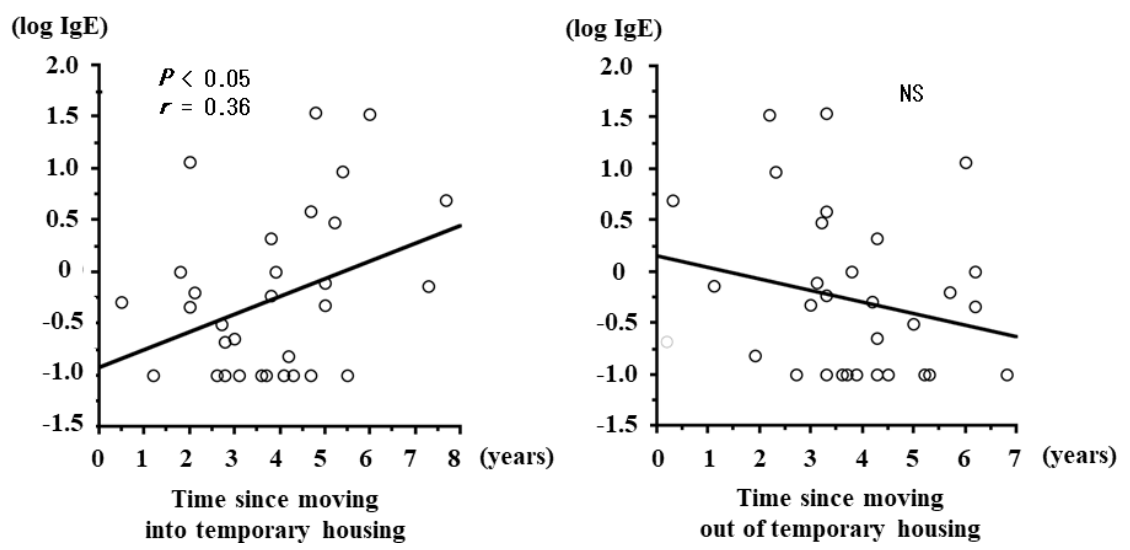

Figure 6 (b)

Log Der p-specific IgE antibody in serum

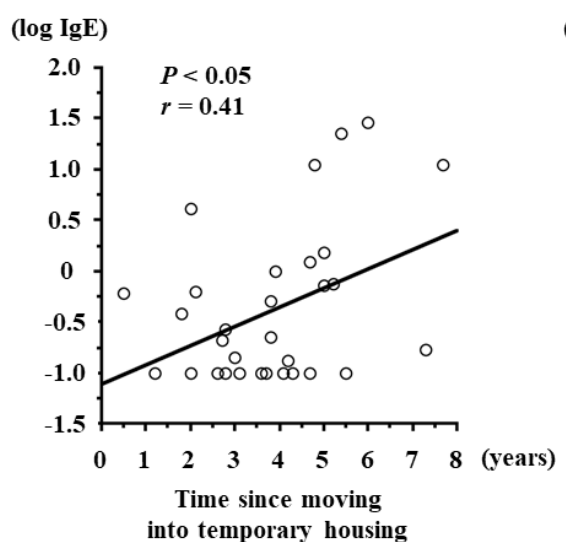

$\log \operatorname{Der} p$-specific IgE antibody in serum



